\title{
Diverticulosis and its complications in the foregut and small bowel
}

\author{
Simon Roh ${ }^{1}$, Yulia N. Matveeva ${ }^{2}$, John Keech $^{3}$, Kalpaj Parekh ${ }^{3}$, Evgeny V. Arshava ${ }^{3}$ \\ ${ }^{1}$ Department of Radiology, St. Luke's University Health Network, Bethlehem, PA, USA; ${ }^{2}$ Department of Family Medicine, ${ }^{3}$ Department of Surgery, \\ University of Iowa Carver College of Medicine, Iowa City, IA, USA \\ Contributions: (I) Conception and design: S Roh, EV Arshava; (II) Administrative support: EV Arshava, K Parekh; (III) Provision of study materials \\ or patients: EV Arshava, K Parekh; (IV) Collection and assembly of data: S Roh, YN Matveeva, EV Arshava; (V) Data analysis and interpretation: All \\ authors; (VI) Manuscript writing: All authors; (VII) Final approval of manuscript: All authors. \\ Correspondence to: Evgeny V. Arshava, MD. Division of Cardiothoracic Surgery, Department of Surgery, University of Iowa Hospitals and Clinics, 200 \\ Hawkins Drive, Iowa City, IA 52242, USA. Email: Evgeny-Arshava@uiowa.edu.
}

\begin{abstract}
Diverticulosis of the foregut and small bowel is uncommon. In this article, we provide an overview of various types of esophageal, gastric, and small bowel diverticula. Asymptomatic diverticula are usually found incidentally during imaging or encountered during unrelated procedures and managed conservatively by observation. Symptomatic patients with esophageal diverticula typically present with dysphagia, regurgitation, and aspiration. These symptoms should prompt elective work-up and treatment. Esophageal diverticulum should be a differential diagnosis for dysphagia, and necessary precaution should be taken during endoscopy to prevent inadvertent perforation. Ideally, patients with dysphagia should be evaluated with imaging prior to endoscopy. Spontaneous perforation and bleeding are very rare, and erosive perforation tends to occur secondary to midesophageal traction diverticula. Gastric, duodenal, and small bowel diverticulosis is frequently asymptomatic. Symptomatic cases may present with obstruction, perforation, and bleeding. While endoluminal techniques have be recently utilized for the management of pharyngoesophageal (Zenker's) diverticulum, other symptomatic and complicated diverticula of the foregut and small bowel required operative treatment. The complications may be life-threatening and require urgent surgical interventions.
\end{abstract}

Keywords: Diverticulosis; esophagus; foregut; small bowel

Received: 25 March 2020; Accepted: 10 July 2020; Published: 25 May 2021.

doi: $10.21037 /$ ccts-20-62

View this article at: http://dx.doi.org/10.21037/ccts-20-62

\section{Introduction}

Based on embryologic development and vascular anatomy, the alimentary tract is divided into the foregut (mouth to proximal duodenum), midgut (which comprises the distal duodenum, the entire small bowel, and extends to the distal third of the transverse colon), and hindgut.

Diverticulum is an abnormal focal protrusion or bulge of the area of wall of the digestive tract. Broadly, diverticula of the gastrointestinal tract can be classified as congenital or acquired. Pathologically, the wall of the true diverticula is formed by all layers of the structure they originate from. False diverticula are only formed by the mucosal layer.

Manifestations of diverticular disease may vary range from a completely asymptomatic state to medically treated illness to life-threatening conditions requiring surgery. "Diverticulosis" indicates merely the presence of these outpouchings even without complications. "Diverticulitis," on the other hand, means inflammatory complications involving these bulges. Other complications, such as bleeding and obstruction, may be associated with diverticular disease as well. Complications of diverticular disease that may require elective or urgent surgical treatment frequently develop in a previously asymptomatic patient and should be promptly diagnosed.

Diverticulosis of the colon is very common, especially in the Western world, and it will not be discussed here. Diverticulosis of the foregut and small bowel are relatively 


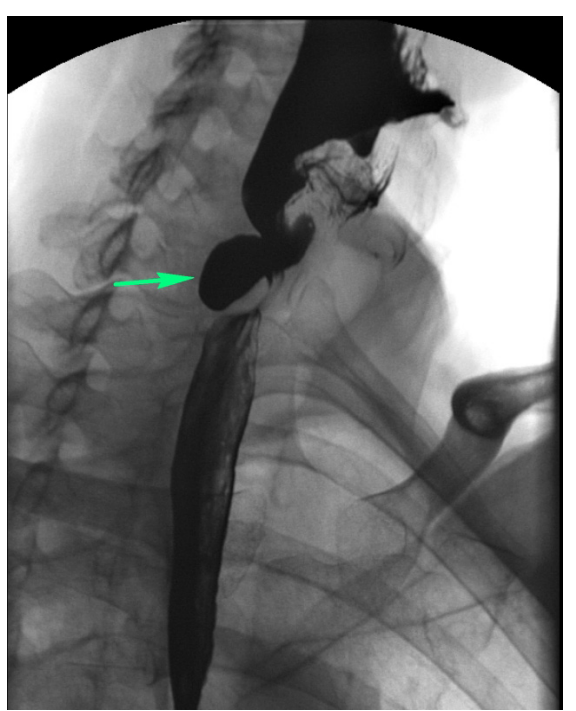

Figure 1 Esophagram showing Zenker's diverticulum (arrow) in a 75 -year-old male presenting with dysphagia, who subsequently underwent uneventful diverticulectomy and myotomy.

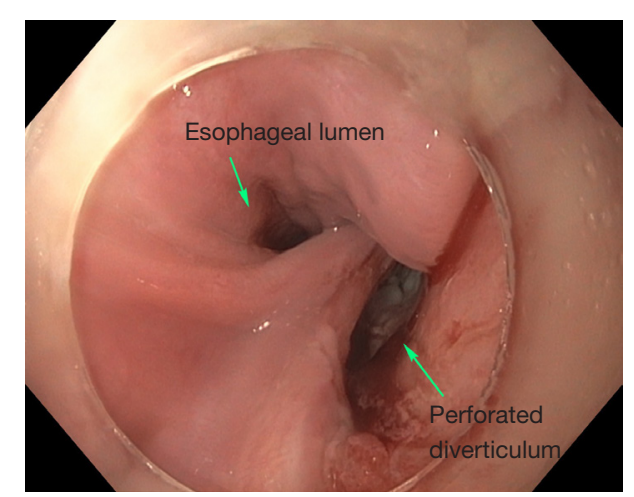

Figure 2 Intraoperative endoscopic image of a 67-year-old patient with an iatrogenic perforation of Zenker's diverticulum requiring urgent repair. The patient initially presented with dysphagia, but the esophagram was not obtained and the presence of diverticulum was not suspected prior to initial endoscopy, which resulted in perforation (courtesy of Rami El Abiad, MD).

uncommon conditions. Various diverticular conditions of the foregut and small bowel and management of their complications are discussed here.

\section{Esophagus}

\section{Pharyngoesophageal (Zenker's) diverticulum}

Zenker's diverticulum is a diverticulum of the cervical esophagus always located at the level of the pharynx through the Killian's triangle, bordered by the thyropharyngeus and cricopharyngeus of inferior pharyngeal constrictor muscles. It develops due to hypertonic dysfunction of the cricopharyngeal muscle (1). This condition is seen most commonly in elderly males (2).

\section{Pathophysiology}

The cricopharyngeus of the inferior pharyngeal constrictor muscle fails to relax, resulting in increased intraluminal pressures proximal to the obstruction, which results in protrusion of mucosa and submucosa through the esophageal wall (3).

\section{Clinical presentation and diagnosis}

Patients with Zenker's diverticulum may present with dysphagia, regurgitation, aspiration, coughing, choking, reflux, and voice changes (3-5). The work-up in elderly patients with such symptoms should start with an esophagram (Figure 1). Proceeding directly with esophagoscopy may pose the risk of diverticulum perforation if this pathology is not considered by the endoscopist prior to the procedure (Figure 2).

\section{Treatment}

Treatment is indicated for all symptomatic patients. Small asymptomatic pharyngoesophageal diverticula found incidentally can be carefully observed. Treatment focuses on relieving the pressure distal to the diverticulum through cricopharyngeal myotomy. Surgical management includes endoscopic diverticulotomy versus operative myotomy with or without diverticulectomy or diverticulopexy (5). The two main modalities in endoscopic treatment are carbon dioxide laser and stapler-assisted techniques $(5,6)$. Endoscopic management has gained popularity because it is minimally invasive and the patient population with this condition is typically elderly with likely multiple medical comorbidities (3). Both open surgery and endoscopic management are considered safe and effective $(1,2,7)$. Endoscopic management offers shorter operative time and hospital stay; however, similar time to initiation of oral diet can be achieved in both endoscopically treated and open surgery patients $(2,4,5)$. The durability of repair is higher among patients undergoing open surgery with myotomy (Figure 3) $(1,4)$.

\section{Traction diverticula of the esophagus}

\section{Pathophysiology}

Traction diverticulum is a true diverticulum in the mid- 


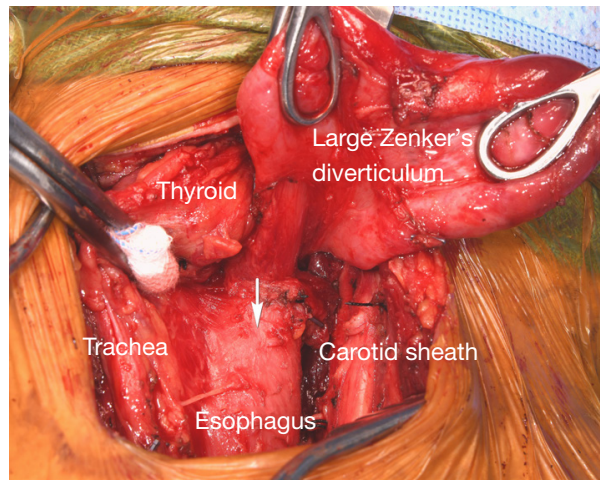

Figure 3 Intraoperative photograph demonstrating a large Zenker's diverticulum and the expected extent of cricopharyngeal myotomy (arrow).

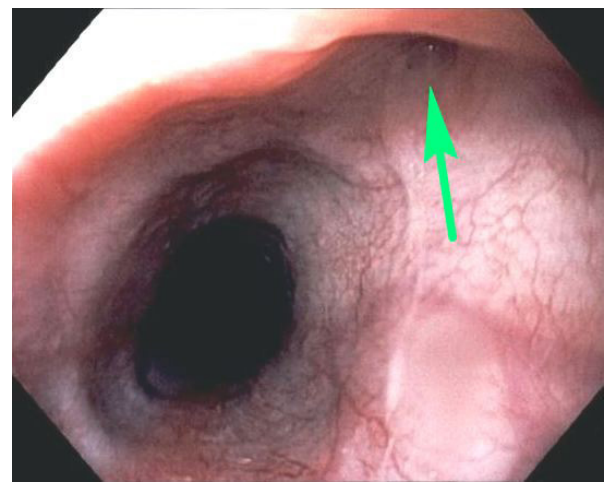

Figure 4 Flexible esophagoscopy demonstrating traction midesophageal diverticulum (arrow) secondary to granulomatous inflammation in an adjacent mediastinal lymph node in a 20 -yearold patient with histoplasmosis.

esophagus that may develop due to adjacent inflammatory changes (8). Inflammation, most commonly of in the form of granulomatous (histoplasmosis or tuberculosis) changes of the mediastinal lymph nodes, creates focal traction on the esophageal wall (3).

\section{Clinical presentation and diagnosis}

These traction diverticula are usually small. Patients are usually asymptomatic and diagnosed incidentally during an imaging examination such as an esophagram obtained for other reasons (3). These diverticula are difficult to see on endoscopy (Figure 4). Over time, ongoing inflammation may result in full-thickness erosion through the esophageal wall with resulting esophagobronchial fistulas (Figure 5), mediastinitis, and other complications.

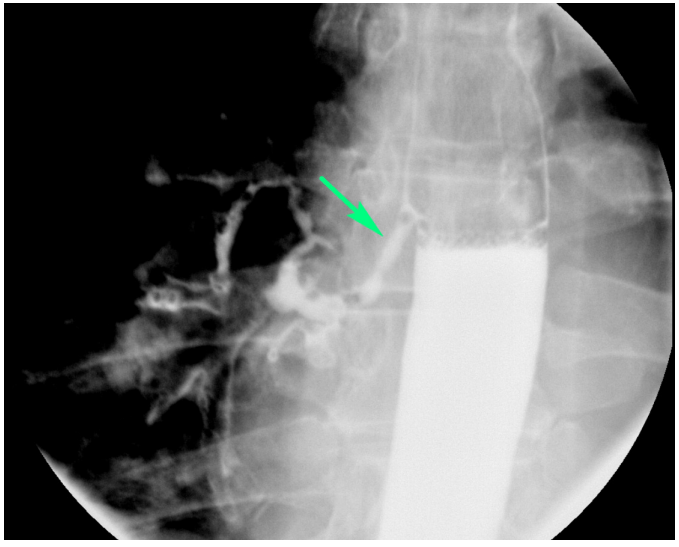

Figure 5 Esophagram showing esophagobronchial fistula (arrow) secondary to erosion of the histoplasmosis necrotizing granuloma into a traction diverticulum in a 43 -year-old male.

\section{Treatment}

Small, incidentally found diverticula may be observed. In cases of large diverticula, a diverticulectomy or diverticulotomy may be performed. An esophagogastric myotomy may be performed with diverticulectomy to decrease the risk of staple line leak (3). There remains controversy regarding surgical management of asymptomatic patients with small diverticula (8).

\section{Pulsion diverticula}

Pulsion diverticulum is a false diverticulum that results from increased intraluminal pressure and that causes the mucosal and submucosal layers to protrude through a focal area of the esophageal wall (8). Pulsion diverticula occur in the midthoracic and distal esophageal regions. Most pulsion diverticula occur in the epiphrenic region. An epiphrenic diverticulum is a subtype of pulsion diverticulum that occurs in the distal $10 \mathrm{~cm}$ of the esophagus $(9,10)$.

\section{Pathophysiology}

Pulsion diverticulum develops due to functional obstruction resulting from esophageal motility disorders such as achalasia, diffuse esophageal spasm, or others $(8,10,11)$. The disorganized contraction within the esophagus results in increased intraluminal pressures, leading to the outpouching of the mucosal and submucosal layers through the muscular layers $(8,10)$. In a certain sense, pulsion diverticula are more distal functional equivalents of Zenker's diverticula. 


\section{Clinical presentation}

Patients with an epiphrenic pulsion diverticulum present with dysphagia, regurgitation, chest pain, heartburn, aspiration, and aspiration pneumonia (10). Patients with a midesophageal pulsion diverticulum may present with dysphagia, intermittent emesis, and substernal chest pain (11) (Figure 6) and very rarely with bleeding. The size of the diverticulum does not correlate to severity of symptoms (9).

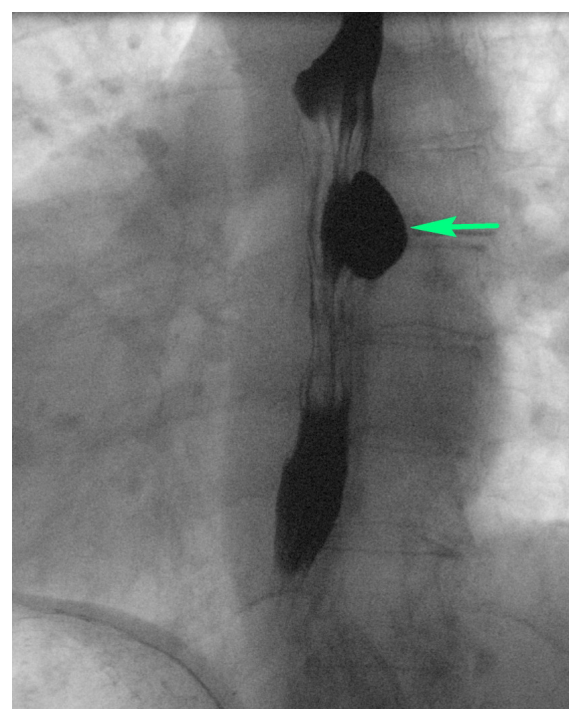

Figure 6 Esophagram of a symptomatic pulsion midesophageal diverticulum (arrow) in a middle-aged patient with dysphagia and underlying spastic motility disorder.

\section{Treatment}

The most common treatment for an epiphrenic pulsion diverticulum consists of diverticulectomy combined with esophageal myotomy (Figure 7). Myotomy is performed to relieve an underlying motility dysfunction. Myotomy must be extended proximally above the level of the diverticulum or above the highest diverticulum present in cases of multiple diverticula. Depending on preoperative findings on esophageal manometry, myotomy may or may not need to be extended across the gastroesophageal junction $(2-3 \mathrm{~cm}$ on to the anterior gastric wall for cases of hypertensive lower esophageal sphincter). Myotomy extended across the gastroesophageal junction needs to be followed by a partial fundoplication to decrease subsequent reflux. Diverticulectomy has been questioned as a necessary procedure, as patients undergoing cardiomyotomy and partial fundoplication without diverticulectomy had no significantly different outcomes. Laparoscopic and thoracoscopic techniques are more commonly used compared to open techniques $(8,10)$. Both techniques have similar outcomes and complication rates, although the minimally invasive technique is associated with shorter hospital length of stay and lower 30-day mortality rates $(8,9)$.

\section{Gastric diverticula}

Gastric diverticulum can present in one of two forms, congenital or, less commonly, acquired (12). Congenitally acquired gastric diverticulum is a true diverticulum and
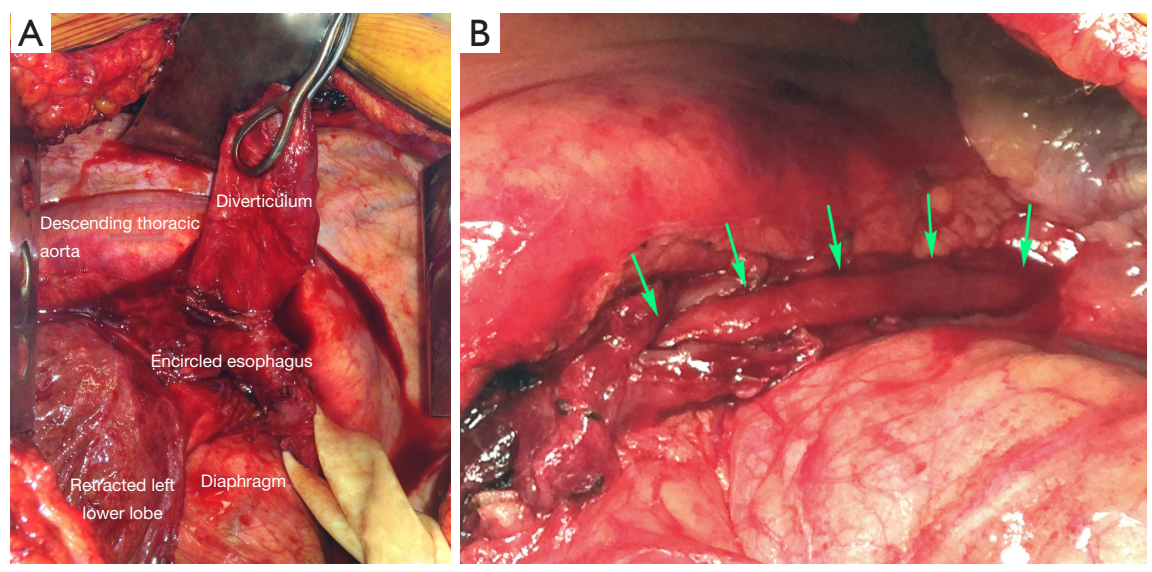

Figure 7 Intraoperative image of a midesophageal pulsion diverticulum before excision and myotomy (A). Arrows show extent of myotomy and exposed esophageal mucosa distal to the resected diverticulum site and through the gastroesophageal junction (B). 


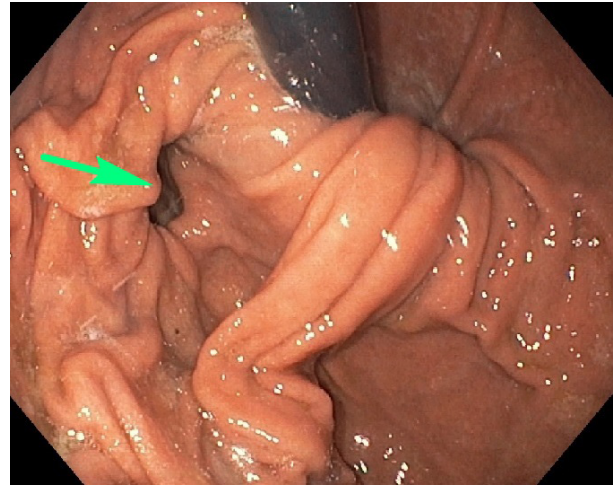

Figure 8 Flexible esophagogastroduodenoscopy demonstrating an incidental finding of gastric diverticulum (arrow) in a patient with gastroesophageal reflux disease (courtesy of Adrian Holm, MD).

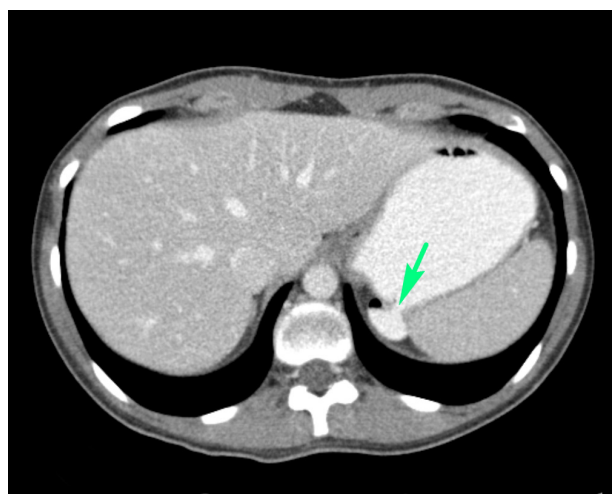

Figure 9 Computed tomography of the abdomen demonstrating an incidental finding of an asymptomatic diverticulum (arrow) in the gastric fundus in a young trauma patient.

is most commonly located on the posterior wall of the fundus, $2 \mathrm{~cm}$ below the gastroesophageal junction and close to the lesser curvature (13-18) (Figure 8). Acquired gastric diverticulum is usually a false diverticulum, is usually located in the distal one-third of the stomach, near the pylorus, and is usually related to inflammatory changes secondary to peptic ulcer disease and pancreatitis, gastric outlet obstruction, or malignancy $(12,15-17)$. Gastric diverticula are very rarely found along the greater curvature (19).

\section{Pathophysiology}

Congenital gastric diverticulum is a result of malformation or interrupted development of the stomach during the fetal period $(16,19)$. Acquired gastric diverticulum develops as either traction or pulsion diverticulum $(12,16,17)$.
Gastric diverticulum arising as traction diverticulum can be due to other disease processes and causes increased intraluminal pressures, such as pyloric obstruction, severe vomiting, coughing, or foreign bodies $(16,17,19)$. Pulsion diverticulum, similar to that found in the esophagus, results from nearby inflammatory processes that cause adhesive forces, leading to outpouching $(12,16,17,19)$.

\section{Clinical presentation}

Patients with gastric diverticulum are usually asymptomatic; the condition is found incidentally on endoscopy or imaging (Figure 9) (18). Those who are symptomatic may present with sensation of fullness or pain in the left upper abdomen after meals, dyspepsia, vomiting, or halitosis $(12,17)$. Cases of spontaneous perforation and bleeding have also been reported. Lack of pathognomonic symptoms makes diagnosis of this condition difficult (20).

\section{Treatment}

Asymptomatic cases can be observed without further treatment $(17,19,20)$. Non-operative management for mildly symptomatic gastric diverticulum includes the use of proton pump inhibitors, antacids, and antispasmodics $(12,17,19,20)$. Non-operative management, however, is not very effective, and symptomatic patients with low risk for general anesthesia should be operated on. Patients with larger diverticula $(>4 \mathrm{~cm})$ and diverticula with a narrow neck tend to be more symptomatic. Surgical management involves open or laparoscopic resection of the diverticulum and is indicated in highly symptomatic cases or symptomatic cases not relieved by medical therapy (Figure 10) (17,19-21).

\section{Duodenum}

\section{Duodenal diverticula}

Duodenal diverticulum is an outpouching of the duodenum and can be present congenitally or it can be acquired $(22,23)$. Congenital diverticulum can be found anywhere along the duodenum. The acquired type is more common than the congenital variant and is usually present along the medial wall of the second and third segments of duodenum (22). The duodenum is the second most common location for diverticula after the colon (24). Duodenal diverticula are more commonly found in women and the elderly (22).

\section{Pathophysiology}

A diverticulum that presents congenitally is a true 


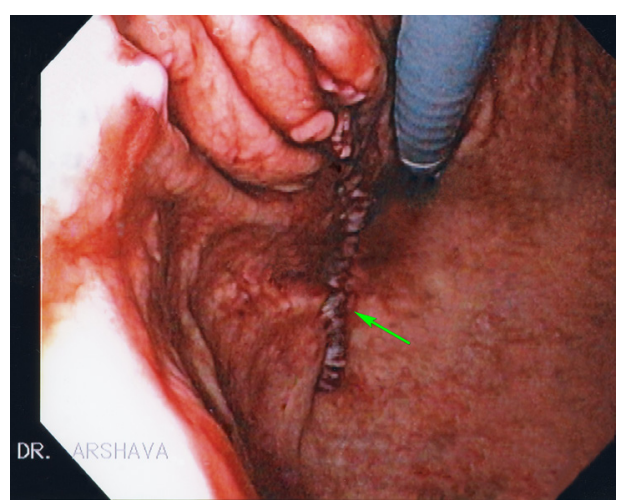

Figure 10 Intraoperative flexible endoscopy demonstrating the staple line (arrow) at the site of a resected gastric diverticulum in a patient with chronic postprandial pain.

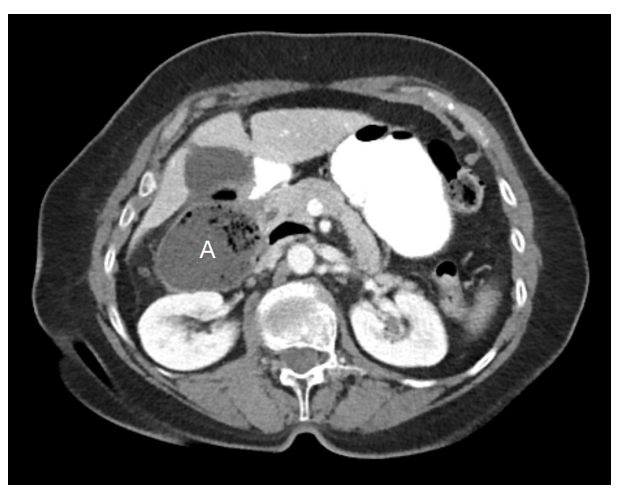

Figure 11 Computed tomography demonstrating a perforated duodenal diverticulum with adjacent abscess (A) formation.

diverticulum and likely arises from maldevelopment of the primitive foregut (22). An intraluminal subtype arises from a spectrum of duodenal recanalization disorders in which a web progressively elongates due to normal duodenal peristalsis (24). An acquired diverticulum is a false diverticulum of the pulsion type from increased intraluminal pressures due to mechanical obstruction, adjacent inflammatory changes, or uncoordinated contraction $(22,23)$.

\section{Clinical presentation}

Patients with duodenal diverticula are usually asymptomatic and, consequently, are diagnosed incidentally on imaging or endoscopy $(22,25)$. Diverticula can cause symptoms if they become perforated or inflamed, or if hemorrhage occurs (25). Diverticulitis is an uncommon condition given the relative sterile environment of the duodenum. Perforation of the diverticulum from extensive inflammation, enterolithiasis, ulceration, foreign body, trauma, iatrogenic causes, or ischemia from distention due to retained food contents can result in abscess formation, fistula to surrounding organs, or obstruction of the common bile duct (Figure 11) (23). If the diverticulum arises in the juxtapapillary or periampullary region, the ampulla and distal common bile duct may be compressed, leading to symptoms of jaundice, biliary cholangitis, or right upper quadrant pain from biliary calculus (22).

\section{Treatment}

Asymptomatic cases may be treated conservatively with observation. In cases of perforated duodenal diverticulum with minimal to mild inflammation, diverticulectomy is performed with a single- or double-layer closure of the duodenum followed by drainage of any residual fluid (25). Another approach to patients with mild symptoms who are poor surgical candidates includes non-operative management with intravenous antibiotics, bowel rest, nasogastric tube decompression, and percutaneous drainage of fluid collections (23). If there are extensive inflammatory changes, primary closure of the duodenum may not be possible, and a Whipple procedure may be indicated (23). Because of the rarity of this condition, there is no standardized treatment protocol $(23,25)$.

\section{Jejunum and ileum}

\section{Non-Meckelian jejunoileal diverticula}

Diverticula found in the jejunum and ileum are rare $(26,27)$. They can be either congenital or acquired (26). This condition is more common among males and is typically found in the sixth or seventh decade of life (28). Diverticula tend to occur along the mesenteric border of the intestine and are found in multiples more proximally in the small bowel (Figure 12) and solitarily in the distal ileum $(26,28,29)$.

\section{Pathophysiology}

Small bowel diverticula are thought to arise from abnormal contractions leading to increased intraluminal pressures $(26,28,29)$. As such, most diverticula thought to be the acquired pulsion type (28). Neurological conditions such as myasthenia gravis are thought to be associated with development of diverticula, as these conditions predispose patients to abnormal contractions within the bowel (27). Diverticula usually occur at the site of intestinal arteries 


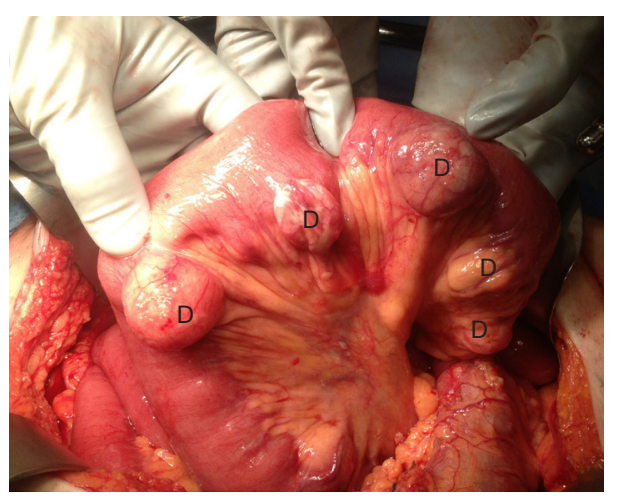

Figure 12 Intraoperative photograph of multiple jejunal diverticula (D) in a patient undergoing laparotomy for unrelated reasons.

penetrating the intestinal muscular layer $(28,29)$. The higher incidence of diverticula in the jejunum compared to the ileum is likely due to the larger size of the penetrating intestinal arteries in the jejunum (27).

\section{Clinical presentation}

Most patients with jejunoileal diverticula are asymptomatic $(26,27,29)$. In the minority of cases that do cause symptoms, patients may present with abdominal pain, nausea, vomiting, anorexia, weight loss, or flatulence (26). More serious complications include acute diverticulitis and perforation, bowel obstruction, traumatic rupture, and volvulus (29). Small bowel diverticula may also present with hematochezia or melena if there is involvement of a perforating intestinal artery with an inflammatory process (27).

\section{Treatment}

Asymptomatic cases are managed conservatively (27). Symptomatic or complicated cases of small bowel diverticula are resected with primary anastomosis $(26,27)$. Given that diverticula arise from the mesenteric side of bowel, primary closure may not be possible, and segmental resection is recommended (28).

\section{Meckel's diverticulum}

Meckel's diverticulum is the most common congenital anomaly of the gastrointestinal tract (30-34). It is found in $2 \%$ of the population, with symptomatic cases having male-to-female predominance of 2:1 to 5:1 $(31,32,35)$. There is no difference in prevalence between genders in asymptomatic cases (35). These diverticula are most commonly found 40 to $100 \mathrm{~cm}$ proximal to the ileocecal valve (30,32-34).

\section{Pathophysiology}

Meckel's diverticulum arises from the anti-mesenteric side of the ileum due to incomplete obliteration of the omphalomesenteric duct (30-34). It is a true diverticulum involving all three layers of the bowel wall (30). Ectopic mucosa can be found in Meckel's diverticulum, with gastric mucosa being the most common (30-32). Less commonly found are ectopic mucosa of pancreatic, duodenal, colonic, endometrial, or hepatobiliary origin.

\section{Clinical presentation}

The majority of patients with Meckel's diverticulum are asymptomatic $(33,34)$. The most common clinical presentation among pediatric patients is painless rectal bleeding due to ulceration in the bowel mucosa secondary to acid-secreting ectopic gastric mucosa within the diverticulum $(30,31,34)$. The higher prevalence of symptomatic cases among males is hypothesized to be due to increased acid-secreting ability within larger parietal cells (35). Among patients presenting with bleeding, the most sensitive test to detect Meckel's diverticulum is a nuclear medicine Meckel's scan (technetium-99m pertechnetate scintigraphy); the radiopharmaceutical is taken up by parietal cells of ectopic gastric mucosa $(30,31,33,34)$. Small bowel obstruction is the second most common presentation of Meckel's diverticulum in the pediatric population, while this is the most common presentation in adults (Figure 13) (30). Inflammation within the diverticulum can lead to diverticulitis, ulceration and perforation with peritonitis, mimicking acute appendicitis (31,35). Symptomatic presentation of Meckel's diverticulum decreases with age, with most patients presenting before 10 years of age and $42 \%$ under the age of 2 years $(30,35)$.

\section{Treatment}

The management of symptomatic Meckel's diverticulum is to perform open or laparoscopic resection of the diverticulum with possible resection of the adjacent bowel if there is vascular compromise, as can be seen in the setting of bowel obstruction (30-32). Diverticulectomy alone is sufficient in cases of bleeding Meckel's diverticulum, as it was shown to have similar outcomes compared to diverticulectomy with bowel resection (32). Incidentally found Meckel's diverticulum during imaging or during surgical procedures performed for other reasons can 


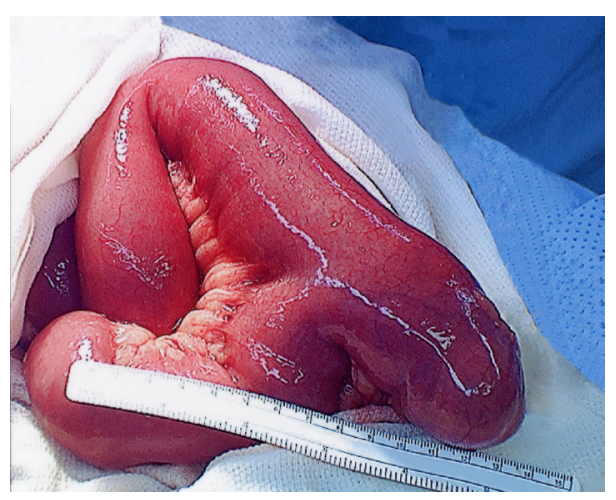

Figure 13 Intraoperative photograph of large Meckel's diverticulum that was serving as a twisting point and a cause of small bowel obstruction.

be managed with close observation only $(30,34)$. Some advocate resection of all incidentally detected Meckel's diverticulum during the abdominal operation (36). The appearance of Meckel's diverticulum during surgery does not indicate whether ectopic gastric mucosa is present or not (31).

\section{Summary}

Diverticulosis of the foregut and small bowel are relatively uncommon conditions, but their complications need to be diagnosed promptly and treated appropriately.

\section{Acknowledgements}

We would like to thank Paul Casella, MFA, University of Iowa Carver College of Medicine Office of Faculty Affairs and Development, for editorial assistance.

Funding: None.

\section{Footnote}

Conflicts of Interest: All authors have completed the ICMJE uniform disclosure form (available at https://ccts. amegroups.com/article/view/10.21037/ccts-20-62/coif). The authors have no conflicts of interest to declare.

Etbical Statement: The authors are accountable for all aspects of the work in ensuring that questions related to the accuracy or integrity of any part of the work are appropriately investigated and resolved.
Open Access Statement: This is an Open Access article distributed in accordance with the Creative Commons Attribution-NonCommercial-NoDerivs 4.0 International License (CC BY-NC-ND 4.0), which permits the noncommercial replication and distribution of the article with the strict proviso that no changes or edits are made and the original work is properly cited (including links to both the formal publication through the relevant DOI and the license). See: https://creativecommons.org/licenses/by-nc-nd/4.0/.

\section{References}

1. Verdonck J, Morton RP. Systematic review on treatment of Zenker's diverticulum. Eur Arch Otorhinolaryngol 2015;272:3095-107.

2. Greene CL, McFadden PM, Oh DS, et al. Long-term outcome of the treatment of Zenker's diverticulum. Ann Thorac Surg 2015;100:975-8.

3. Smith CD. Esophageal strictures and diverticula. Surg Clin North Am 2015;95:669-81.

4. Shahawy S, Janisiewicz AM, Annino D, et al. A comparative study of outcomes for endoscopic diverticulotomy versus external diverticulectomy. Otolaryngol Head Neck Surg 2014;151:646-51.

5. Wilken R, Whited C, Scher RL. Endoscopic staple diverticulostomy for Zenker's diverticulum: review of experience in 337 cases. Ann Otol Rhinol Laryngol 2015;124:21-9.

6. Parker NP, Misono S. Carbon dioxide laser versus staplerassisted endoscopic Zenker's diverticulotomy: a systematic review and meta-analysis. Otolaryngol Head Neck Surg 2014;150:750-3.

7. Jackson B, Ahmad Z, Morton RP. Utility of transcervical management of Zenker's diverticulum. J Laryngol Otol 2016;130 Suppl 1:S16-9.

8. Macke RA, Luketich JD, Pennathur A, et al. Thoracic esophageal diverticula: A 15 -year experience of minimally invasive surgical management. Ann Thorac Surg 2015;100:1795-802.

9. Andolfi C, Wiesel O, Fisichella PM. Surgical treatment of epiphrenic diverticulum: technique and controversies. J Laparoendosc Adv Surg Tech A 2016;26:905-10.

10. Fisichella PM, Jalilvand A, Dobrowolsky A. Achalasia and epiphrenic diverticulum. World J Surg 2015;39:1614-9.

11. Khullar OV, Shroff SR, Sakaria SS, et al. Midesophageal Pulsion Diverticulum Resulting From Hypercontractile (Jackhammer) Esophagus. Ann Thorac Surg 
2017;103:e127-9.

12. Donkervoort SC, Baak LC, Blaauwgeers JL, et al. Laparoscopic resection of a symptomatic gastric diverticulum: a minimally invasive solution. JSLS 2006; 10:525-7.

13. Gockel I, Thomschke D, Lorenz D. Gastrointestinal: Gastric diverticula. J Gastroenterol Hepatol 2004;19:227.

14. Greenfield J, Rossett NE, Mendel WH. Gastric diverticula. Arch Surg 1950;60:65-74, illust.

15. MaCauley M, Bollard E. Gastric diverticulum: a rare cause of refractory epigastric pain. Am J Med 2010;123:e5-6.

16. Moses WR. Diverticula of the stomach. Arch Surg 1946;52:59-65.

17. Podda M, Atzeni J, Messina Campanella A, et al. Syncope with surprise: an unexpected finding of huge gastric diverticulum. Case Rep Surg 2016;2016:1941293.

18. Velanovich V. Gastric diverticulum. Endoscopic and radiologic appearance. Surg Endosc 1994;8:1338-9.

19. Cotea E, Vasilescu A, Dimofte G, et al. Gastric Diverticulation on the greater curvature. Jurnalul de Chirurgie, Iasi 2007;3(3). [ISSN 1584 - 9341].

20. Rashid F, Aber A, Iftikhar SY. A review on gastric diverticulum. World J Emerg Surg 2012;7:1.

21. Rodeberg DA, Zaheer S, Moir CR, et al. Gastric diverticulum: a series of four pediatric patients. J Pediatr Gastroenterol Nutr 2002;34:564-7.

22. Dusunceli Atman E, Erden A, Ustuner E, et al. MRI Findings of intrinsic and extrinsic duodenal abnormalities and variations. Korean J Radiol 2015;16:1240-52.

23. Song S. Management of perforated duodenal diverticulum: report of two cases. Korean J Gastroenterol 2015;66:159-63.

24. Schroeder TC, Hartman M, Heller M, et al. Duodenal diverticula: potential complications and common imaging pitfalls. Clin Radiol 2014;69:1072-6.

25. Fujisaki S, Takashina M, Sakurai K, et al. Simple diversion

doi: $10.21037 /$ ccts-20-62

Cite this article as: Roh S, Matveeva YN, Keech J, Parekh K, Arshava EV. Diverticulosis and its complications in the foregut and small bowel. Curr Chall Thorac Surg 2021;3:15. by duodenojejunostomy for a retroperitoneal perforation of the second portion of the duodenal diverticulum. Int Surg 2014;99:628-31.

26. Karas L, Asif M, Chun V, et al. Complicated small bowel diverticular disease: a case series. BMJ Case Rep 2017;2017:bcr2017219699.

27. Mantas D, Kykalos S, Patsouras D, et al. Small intestine diverticula: Is there anything new? World J Gastrointest Surg 2011;3:49-53.

28. Roses DF, Gouge TH, Scher KS, et al. Perforated diverticula of the jejunum and lleum. Am J Surg 1976;132:649-52.

29. Axelrod H. Non-meckelian diverticula of the jejunum and ileum. Am J Surg 1954;88:405-10.

30. Chatterjee A, Harmath C, Vendrami CL, et al.

Reminiscing on remnants: imaging of Meckel diverticulum and its complications in adults. AJR Am J Roentgenol 2017;209:W287-96.

31. Morris G, Kennedy A Jr, Cochran W. Small bowel congenital anomalies: a review and update. Curr Gastroenterol Rep 2016;18:16.

32. Glenn IC, El-Shafy IA, Bruns NE, et al. Simple diverticulectomy is adequate for management of bleeding Meckel diverticulum. Pediatr Surg Int 2018;34:451-5.

33. Irvine I, Doherty A, Hayes R. Bleeding Meckel's diverticulum: a study of the accuracy of pertechnetate scintigraphy as a diagnostic tool. Eur J Radiol 2017;96:27-30.

34. Lequet J, Menahem B, Alves A, et al. Meckel's diverticulum in the adult. J Visc Surg 2017;154:253-9.

35. Celebi S. Male predominance in Meckel's diverticulum: a hyperacidity hypotheses. Med Hypotheses 2017;104:54-7.

36. Cullen JJ, Kelly KA, Moir CR, et al. Surgical management of Meckel's diverticulum. An epidemiologic, populationbased study. Ann Surg 1994;220:564. 